\title{
New Opportunities to Expand Information on Intense-Strained State of the Earth's Crust in the Areas of Development Mineral Resources During Monitoring Creation
}

\author{
Vladimir Pershin ${ }^{1 *}$, and Aleksander Solovitskiy ${ }^{1}$ \\ ${ }^{1}$ T.F. Gorbachev Kuzbass State Technical University, 650000, 28 Vesennyaya St., Kemerovo, Russia
}

\begin{abstract}
It is established that new safe and pollution-free technologies of development of Kuzbass coal deposits should be based on new knowledge of development geodynamic and technogenic processes in exploration of mineral resources. Such information is impossible without formation of new models of deformations of the earth crust blocks. Now in traditional technologies of geomechanical ensuring development of mineral resources the main characteristic is the information about the kinematics of these processes. A comprehensive approach which beginning is development of the theory for justification of scale of the explored territory and establishment of uniform integral parameters of a strained state of blocks of crust. Justification of scale of the explored territory defines effectiveness of expenses. Establishment of uniform integral parameters of a strained state of crustal blocks characterizes the new level of information exchange between sciences about Earth and geomechanics. Practical use of the specified theory consists of assessment of geodynamic danger at development of coal fields.
\end{abstract}

\section{Introduction}

Traditional technologies of mineral resources development are focused on studying their geomechanical conditions by improving the information on the intense-strained state of the rock mass [1-3]. Therefore, in practice the dominating development is gained by geophysical and surveying methods. The new stage of development of studying intensestrained state of a block of rock mass is not observed after the fundamental research 80 -ties and 90 -ties. There are some reasons.

1. The absence of a unified technological policy.

2. Training Costs.

2. The pursuit of profit.

All three specified reasons are interrelated, therefore, obtaining new information and new knowledge of an intense strained state of crust is restrained. However, it should be noted that a tendency of development of the modern technologies of Earth Sciences is to improve the accuracy, efficiency and automation of processes such as the measurement of

*Corresponding author: pvv.spssh@,kuzstu.ru 
production and processing of the received information [4-6]. Therefore, they are in demand for studying of natural and technogenic geodynamic processes in the development of the coalfields, information about which is the most important in the aspect of forecast catastrophic geodynamic phenomena (life threatening situations). However, despite the material and human losses, systemic monitoring of natural and technogenic geodynamic processes at development of coalfields is not developed. Occasionally re-performed monitoring of technogenic geodynamic polygons (GFC) is ambiguous, time-consuming, not sufficiently detailed and operational. Therefore, the development of theory and methods of geodetic monitoring of the stress-strain state of the crust (GMDSS) in the areas of development of coal deposits, ensuring the safety of their development, is a scientific issue with important socio-economic importance. Its development is constrained by lack of new mathematical models of geodetic constructions on the geodynamic polygons allowing registering; evaluating and predicting the stress-strain state of the earth's crust [7-12]. The main condition for such models is the relationship between changes in the coordinates of points obtained from repeated observations, with parameters of the stress-strain state (SSS) of the earth's crust, as they are not available by direct measurement of geodetic methods. The objective of this monitoring is the collection, storage, processing, and analysis and forecast information on the stress-strain state of the crust during the development of coal deposits to reduce the risk of manifestations of geodynamic phenomena (life threatening situations). The statement allows to consider the actual development of theory and methods GMDSS in the areas of development of coal deposits.

\section{Results and discussion}

Acquiring new knowledge about the state of a block of the earth's crust based on the results GMDSS is necessary for its evaluation, analysis and use [13]. This will require the following:

- establishing one number of the earth crust block;

- the establishment of common integral parameters of intense-strained state of the earth crust blocks;

- assessment of the scale of the investigated area.

A modern approach to the use of the results GMDSS is based on information technology, therefore, the following classification is proposed which includes the region code, year, and method of execution, as well as the hierarchy structure of the crust. The proposed single number of block of the earth's crust has the following structure:

- the region code;

- the year of the;

- the method of implementation;

- a rank unit;

- hierarchical room

The region code corresponds to the political-administrative division of Russian Federation and determines its subject. The procedure is determined by table 1 .

Table 1. The code of the method of geodynamic zoning.

\begin{tabular}{|l|c|}
\hline Method & Code \\
\hline Geological & 01 \\
\hline Geophysical & 02 \\
\hline Geomorphologic & 03 \\
\hline Cartographic & 04 \\
\hline Remote sensing & 05 \\
\hline Integrated & 06 \\
\hline
\end{tabular}


The rank of a block is determined by the adopted hierarchy structure of the crust, so at geodynamic zoning of Kuzbass six rank system is applied, so the hierarchical number will be a 12-digit number, for example, 42:1987:04: 03: 000001000000.

The establishment of common integral parameters of intense-strained state of the earth crust blocks eliminates the ambiguity of the kinematic characteristics of the crustal blocks of different ranks used in traditional technologies. Quantitative characteristics of vertical and horizontal movements of the earth's crust are the amplitudes $\Delta \mathrm{A}_{j}\left[t-t_{0}\right]$ [6] determined by the difference of coordinates $\Delta \mathrm{A}_{1}\left[t-t_{0}\right]=\left(X[\mathrm{t}]-X\left[\mathrm{t}_{0}\right]\right), \Delta \mathrm{A}_{2}\left[t-t_{0}\right]=\left(\mathrm{Y}[\mathrm{t}]-\mathrm{Y}\left[\mathrm{t}_{0}\right]\right)$ и $\Delta \mathrm{A}_{3}\left[t-t_{0}\right]=H[\mathrm{t}]-H\left[\mathrm{t}_{0}\right]$ of the same items at different times $\mathrm{t}$ and $\mathrm{t}_{0}$ according to the formulas:

$$
\Delta \mathrm{A}\left[t-t_{0}\right]=\mathrm{A}[\mathrm{t}]-\mathrm{A}\left[\mathrm{t}_{0}\right]
$$

where $j=x, y, z$.

The most common presentation of quantitative characteristics of movements of crustal blocks on the results of the analysis is shown in the table 2 .

Table 2. Representation of the quantitative characteristics of the movements of the earth's crust

\begin{tabular}{|l|l|}
\hline \multicolumn{2}{|c|}{ Type of presentation of quantitative characteristics } \\
\hline Tabular & Tables \\
\hline The amplitudes & Charts \\
\hline Speed & Vector schemes \\
\hline Gradients & Maps \\
\hline
\end{tabular}

To substantiate these parameters, the authors carried out the following experiment. For blocks of the crust of the studied grades in the areas of development of deposits using the programme "BM" the time variation of deformations of crustal blocks of Kuzbass is modeled based on their kinematics, which are shown in the figure 1.

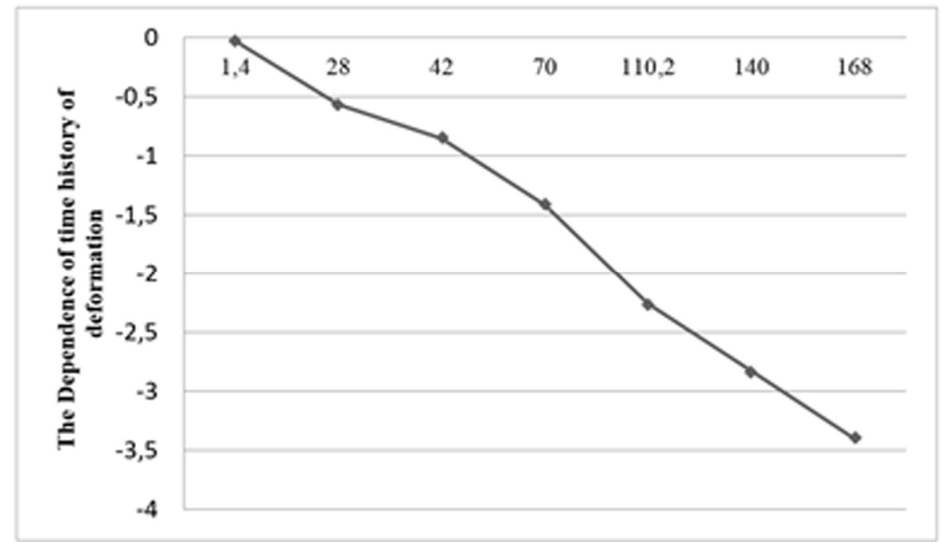

Fig. 1. The Dependence of time history of deformation of the block of crust of III rank on the speed of its velocity: the vertical axis-strain variation in time blocks of the crust $\left(1 \cdot 10^{-6}\right)$; the horizontal axis is the velocity of motion of the earth blocks ( $\mathrm{mm} /$ year).

The received dependences by results of researches confirm that the same values of time variation of the deformation of crustal blocks of different grades correspond to different 
velocities of their movements. Because of this difference in the velocities of the movements of the blocks of the earth's crust of different ranks corresponding to the same values of the time variation of their deformations, the kinematic characteristics of the blocks of the earth's crust can not be accepted as dynamic parameters of the crustal block. A more acceptable option is the time variation of deformations of blocks of the earth's crust, which are integral characteristics. Thus, the dynamic parameters are the changes over time of deformation (stresses) and the potential energy determining the kinematics of earth crust block. To determine the dynamic parameters of the earth's crust, the author optimized and compiled the program "BM" [13].

The integral nature of these parameters is to provide a new level of information interaction between the Geosciences and geomechanics. In addition, changes in time of the deformation of the crustal blocks are expressed analytically depending on the corresponding changes of stress and potential energy, that is, of the entire range of considered parameters, which quantitatively characterize the manifestation of geodynamic phenomena (life threatening situations). The obtained dependences allow assessing the scale of the studied area of coal companies. Defined by the authors of the program "BM" based on changes over time of the potential energy and density from the ranks of the crustal blocks of Kusbass are shown in the figures 2 .

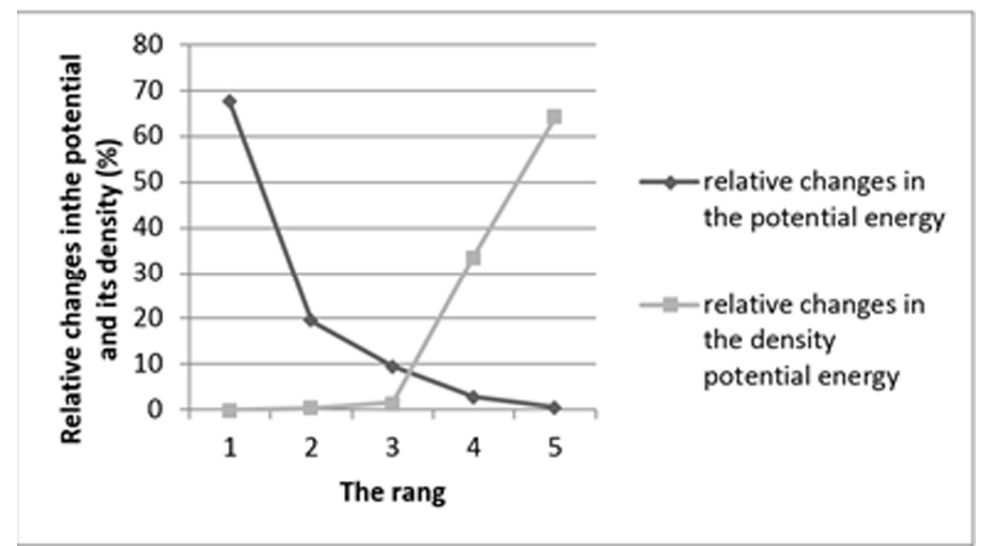

Fig. 2. The dependence of the change in the time of the potential energy and its density from the ranks of the crustal blocks

The results which are shown in the figure 2 demonstrate that the variation in time of the potential energy of deformation of crustal blocks of Kuzbass are in inverse proportion to their rank (of $67 \%$ in unit II rank and $1 \%$ in unit VI rank ), and the corresponding change of its density (64\% in unit VI rank and $0.5 \%$ in units II and III rank) in a straight line. Such dependencies can be obtained for a block of the earth's crust of any field. The received dependences regulate the scale of studying of dynamic parameters of blocks of crust around development of the field. According to the results shown in the figure 2, the most popular territory for the study will be the territory of the crustal blocks of the V-th and VI-th rank.

\section{Conclusions}

Based on the results of the research the author has developed a theory that defines the basics of creating GMDSS, and made the following conclusions:

1. Justification and establishment of dynamic block parameters of the earth's crust provide: disambiguation of kinematic characteristics; a new level of information interaction 
between the Earth Sciences and geomechanics; to assess the scale of the studying area of coal companies.

2. It is established that the variation in time of the potential energy of deformation of crustal blocks of Kuzbass is in inverse proportion to their rank and the corresponding change of its density in a straight line.

3. Quantitative changes over time of the potential energy of deformation of the crustal blocks and the corresponding change of its density indicate that the most popular for studies in the areas of development of deposits are areas of crustal blocks of the V-th and VI-th rank.

4. Proposed a unified numbering blocks of the earth's crust in the area of development creates GMDSS and eliminates the uncertainty of the crustal structure.

\section{References}

1. A. A. Kozyrev, I. E. Semenova, V.V. Rybin, I. M. Avetisyan, Journal of Mining Science, 51, 4 (2015).

2. B. G. Saksin, I. Y. Rasskazov, B. F. Shevchenko, Journal of Mining Science, 51, 2 (2015).

3. G. G. Kocharyan, A. A. Ostapchuk, Journal of Mining Science, 51, 1(2015).

4. A. A. Mylnikova, Yu. V. Yasyukevich, E. V. Kunitsyu, Results in Physics. 5, (2015).

5. A. P. Karpik, I. G. Ganagina, S. N. Kosarev, D. N. Goldobin, Gyroscopy and Navigation, 7, 1(2016).

6. A. N. Solowizkij, Journal of Shandong Mining Institute. 16, (1997).

7. C. DeMets, R. G. Gordon, D. F. Argus, Geophys Journal Int., 181, (2010)

8. D. F. Argus, R. G. Gordon, M. B. Heflin, C. Ma, R. J. Eanes, P. Willis, W. R. Peltier, S. Owen, Geoophys Journal Int., 180, (2010).

9. R. McCaffrey, Journal Geophys. Res.,110, B07401(2005)..

10. J. C. Savage, W. Gan, J. L. Svarc, Journal Geophys. Res., 106, ( 2001)

11. Z. Shen, D. D. Jackson, B. X. Ge, Journal Geophys. Res., 101, (1996).

12. A. Solovitskiy, 8th Russian-Chinese Symposium. Coal in the 21 st Century: Mining, Processing and Safety, 2, 255-260 (2016) 
